Научная статья

УДК 316.442

DOI: $10.17213 / 2075-2067-2021-5-61-69$

\title{
ФАКТОРЫ ФОРМИРОВАНИЯ ТУРИСТСКИХ ПРАКТИК СТАРШЕГО ПОКОЛЕНИЯ (ПО МАТЕРИАЛАМ ЭКСПЕРТНЫХ ИНТЕРВЬЮ)
}

\author{
Алена Игоревна Черевкова \\ Южный федеральный университет, Ростов-на-Дону, Россия \\ yaitskova_a@mail.ru, ORCID:0000-0003-0662-226, \\ AuthorID РИНЦ: 1016048, SPIN-код: 6404-2082
}

\begin{abstract}
Аннотация. Цель исследования состоит в выявлении групп факторов, оказываюших влияние на формирование туристских практик старшего поколения для дальнейшей разработки стратегий повышения туристской активности данной возрастной группь.

Методологическую базу составляют структуралистско-конструктивистский подход и теория структурации, которые позволяют рассматривать туристские практики как совокупность устойчивых и воспроизводимых социальными акторами действий, реализуемых в туристских цеелях под влиянием экзогенных и эндогенных факторов институциональной средьл.
\end{abstract}

Эмпирической базой работы выступают результаты опросов, проведенных ведущиими сочиологическими иентрами (ВЦИОМ, Левада-Центр и др.) в 2017-2021 г2., данные статистики, представленные Ростуризмом, статистические данные Росстата, а также 6 неструктурированных интервью с экспертами в области развития туризма Ростовской области, проведенных автором в мае-июле 2021 г.

Результаты исследования. На основании опросов населения констатируется низкая вовлеченность старшего поколения России в туристские практики, что обуславливается комплексом факторов, которые не сводятся к экономическим (низкие пенсии) или эпидемиологическим. Барьерами выступают плохое состояние здоровья, недостаточное развитие информационно-коммуникационных навыков у значительной части пожильх людей, а также политические факторы и фокус СМИ на угрозах и опасностях, с которыми может столкнуться турист. Не способствуют повышению туристской активности старшего поколения отсутствие специализированных федеральных и региональных программ, несоответствие предлагаемых туристских услуг материальным и физиологическим возможностям и потребностям пожильх людей.

Перспективы исследования. Многофакторность исследуемой проблемы взывает к необходимости социологической экспертизы с помощью проведения глубинных интервью с представителями старшего поколения. Это позволит своевременно выявлять потребности старшей возрастной группы в туристских практиках, ее ожидания, планы, опасения и причины, препятствующче совершению турпоездок, и в соответствии с ними вьстраивать систему стратегий повышения туристской активности.

Ключевые слова: туризм, сочиология туризма, сочиильные практики, туристские практики, пандемия коронавируса, старшее поколение, экспертное исследование, Ростовская область

(C) Черевкова А.И., 2021 
Для цитирования: Черевкова А.И. Факторы формирования туристских практик старшего поколения (по материалам экспертных интервью) // Вестник Южно-Российского государственного технического университета. Серия: Социально-экономические науки. 2021. T. 14, №5. C. 61-69. http://dx.doi.org/10.17213/2075-2067-2021-5-61-69.

Благодарности: исследование выполнено при финансовой поддержке РФФИ в рамках научного проекта №20-311-90036 «Дифференциация туристских практик населения Ростовской области в условиях социального неравенства в российском обществе».

Original article

\title{
FORMATION FACTORS OF THE OLDER GENERATION' TOURIST PRACTICES (BASED ON THE MATERIALS OF EXPERT INTERVIEWS)
}

\author{
Alena I. Cherevkova
}

\author{
Southern Federal University, Rostov-on-Don, Russia \\ yaitskova_a@mail.ru,ORCID:0000-0003-0662-226, \\ AuthorID RSCI: 1016048, SPIN: 6404-2082
}

\begin{abstract}
The purpose of the study is to identify groups of factors that influence the formation of the older generation' tourist practices for further development of strategies to increase tourist activity of this age group.

The methodological basis of the research consists of the structuralist-constructivist approach and the theory of structuration, which allow us to consider tourist practices as a set of stable and reproducible actions by social actors, implemented for tourist purposes under the influence of exogenous and endogenous factors of the institutional environment.

The empirical basis of the work is the results of surveys conducted by leading sociological centers (WCIOM, Levada Center) in 2017-2021, statistical data provided by Federal Agency for Tourism, statistical data of the Federal State Statistics Service, as well as 6 unstructured interviews with experts in the field of tourism development of the Rostov region, conducted from May to July 2021.

The results of the study. Based on population surveys, the low involvement of the older generation in Russia in tourist practices is stated. This is due to a complex of factors that are not reduced to economic (low pensions) or epidemiological. There are barriers to the implementation of tourist practices: poor health, insufficient development of information and communication skills of a significant part of the elderly, as well as political factors and media focus on the threats and dangers that a tourist may face. The lack of specialized federal and regional programs, the discrepancy between the offered tourist services and the material and physiological capabilities and needs of older people do not contribute to the increase in the tourist activity of the older generation.

The prospect of the study. The multifactorial nature and complexity of the problem under study call for a deep sociological examination, including in-depth interviews with representatives of the older generation. This will make it possible to timely identify the needs of the older age group in tourist practices, their expectations, plans, fears and reasons that prevent them from making tourist trips, and in accordance with them to create a strategies for increasing tourist activity.
\end{abstract}

Keywords: tourism, sociology of tourism, social practices, tourist practices, the coronavirus pandemic, the older generation, expert research, Rostov region 
For citation: Cherevkova A.I. Formation factors of the older generation' tourist practices (based on the materials of expert interviews) // Bulletin of the South Russian State Technical University. Series: Socio-economic Sciences. 2021; 14(5): 61-69. (In Russ.). http://dx.doi. org/10.17213/2075-2067-2021-5-61-69.

Acknowledgments: the reported study was funded by RFBR according to the research project №20-311-90036 «Differentiation of tourist practices of the Rostov region population in the conditions of social inequality in the Russian society".

Введение. Глобальная демографическая тенденция старения населения в полной мере проявляется в России: на 1 января 2021 г. доля населения в возрасте 60 лет и старше составила $22,36 \%(32,8 \text { млн. человек })^{1}$. По данным опроса ВЦИОМ 2020 г., среди проблем, с которыми сталкиваются пожилые люди в России, респондентами отмечаются ухудшение здоровья, болезни (44\%), ощущение ненужности, невостребованности в обществе $(19 \%)$, одиночество (17\%), отсутствие активной деятельности $(7 \%)^{2}$.

Одним из эффективных способов профилактики апатии, поддержания здоровья и социальной активности, улучшения социального самочувствия выступает туризм. Он играет важную роль в физическом и духовном развитии человека, оказывает оздоровительное и восстанавливающее воздействие. В Стратегии действий в интересах граждан старшего поколения до 2025 г. отмечается, что путешествие является «уникальным средством реабилитации, дает возможность расширять круг общения по интересам, устанавливать независимые и разнообразные контакты, которые помогают получить уверенную и эффективную жизненную поддержку, необходимую человеку старшего поколения» ${ }^{3}$.

Однако туристская активность старшего поколения в России остается понижен- ной в сравнении с европейскими странами, США, Канадой, Японией, Южной Кореей. Так, например, в Китае туристы старше 60 лет в 2015 г. составили 58\% всего турпото$\mathrm{ka}^{4}$, а в Евросоюзе до начала пандемии коронавируса люди старше 65 лет составляли пятую часть от общего количества путешественников ${ }^{5}$. В России, по данным телефонного опроса, проведенного компанией Ipsos в 2018 г., за предшествующий исследованию год по России путешествовали $12 \%$ респондентов из числа пенсионеров в возрасте 60 75 лет, проживающих в городах с населением свыше 100 тыс. человек 6 . За пределы России выезжали 6\% опрошенных 60-75 лет. Представители старшей возрастной группы ездят в турпоездки меньше, чем более молодые, и распространенность туризма как социальной практики пожилого населения невысока, в связи с чем представляется важным исследовать факторы, которые оказывают влияние на формирование туристских практик пожилых людей - их мотивацию к туризму или отказу от него, выбор конкретных направлений и видов туризма.

Туризм старшего поколения рассматривается в методологических рамках структуралистско-конструктивистского подхода П. Бурдье и теории структурации Э. Гидденса $[1 ; 2]$. Туристские практики понимаются

1 Старшее поколение [Электронный ресурс] // Федеральная служба государственной статистики. URL: https://rosstat.gov.ru/folder/13877.

2 Продолжительность жизни в России: желания и реальность [Электронный ресурс] // ВЦИОМ. 4 декабря 2020 г. URL: https://old.wciom.ru/index.php?id=236\&uid=10659.

3 Стратегия действий в интересах граждан старшего поколения в Российской Федерации до 2025 года // Официальный сайт Правительства РФ. URL: http:/government.ru/docs/21692/.

4 Chinese elderly people go on a trip [Electronic resource] // Chinese Tourists Agency. URL: https://www. chinesetouristagency.com/chinese-elderly-people-go-on-a-trip/.

51 in 5 tourism nights of EU residents spent by tourists aged 65 or over // Eurostat. URL: https://ec.europa.eu/ eurostat/documents/2995521/7664325/4-26092016-AP-EN.pdf/59bc5872-a0e0-4666-99b3-073a82672e71.

6 Сколько российских пенсионеров ездят в турпоездки и куда // Ассоциация туроператоров России. URL: https://www.atorus.ru/news/press-centre/new/47221.html. 
как совокупность устойчивых и воспроизводимых социальными акторами действий, реализуемых в туристских целях под влиянием экзогенных и эндогенных факторов институциональной среды. Туризм, следуя нормативно закрепленному определению, рассматривается как временные выезды (путешествия) с постоянного места жительства «в лечебно-оздоровительных, рекреационных, познавательных, физкультурно-спортивных, профессионально-деловых и иных целях без занятия деятельностью, связанной с получением дохода от источников в стране (месте) временного пребывания» ${ }^{7}$. Структуралистский конструктивизм представляет собой методологическую основу для изучения социальных практик с учетом разнообразных факторов социальной жизни: габитуса акторов практик, их капитала, а также факторов социального поля [3]. В рамках данной статьи рассмотрим капитал и факторы поля как переменные, формирующие туристские практики старшего поколения.

Эмпирическую базу исследования составляют результаты опросов, проведенных ведущими социологическими центрами в период 2017-2021 гг., данные статистики, представленные Ростуризмом, статистические данные Федеральной службы государственной статистики, а также 6 неструктурированных интервью с экспертами в области развития туризма Ростовской области, проведенных в мае-июле 2021 г. По два интервью было проведено с имеющими ученую степень представителями академического сообщества, в чьи научные интересы входит изучение туризма (эксперты №1 и №2); с представителями органов власти, в сферу деятельности которых входит развитие туризма (эксперты №3 и №4); с сотрудниками туроператоров и турагентств, осуществляющих свою деятельность на территории Ростовской области (эксперты №5 и №6).
Результаты. Как показал анализ экспертных интервью, важнейшим фактором формирования туристских практик выступает экономический капитал пожилых людей. Эксперты считают материальный достаток основным фактором, детерминирующим выбор индивидом любого возраста тех или иных практик, а низкий уровень материального обеспечения - главным барьером, ограничивающим туристскую активность пожилых людей: «Очень важен такой момент, как материальная состоятельность пожилых туристов. В Европе вышел на пенсию - и до конца жизни обеспечен, можешь путешествовать. В России вышел на пенсию и, к сожалению, в большинстве своем, доживаешь. В мире $80 \%$ путешествуюших - это пожилье, 20\% - все остальныле. В России ровно наоборот» (эксперт №3); «Путешествует человек, которого поддерживают дети, или у него есть свой бизнес, или он ещзе работает, востребованньй специалист, у которого финансовая подушка обширная, но объективно очень маленький процент этих пенсионеров» (эксперт №5). Низкие пенсии и уровень жизни из года в год в опроcax населения указываются как главные проблемы старшего поколения. Минимальный размер пенсии в России на 1 января 2021 г. 9311 руб., а средний размер назначенных пенсий по старости - 15744,6 руб. ${ }^{8}$, что при отсутствии дополнительных источников дохода оказывается не достаточным для удовлетворения даже базовых потребностей.

Однако необходимо учитывать, что часто пенсия - это не единственный источник финансов: достигнув пенсионного возраста, многие продолжают работать (20,7\% населения старше трудоспособного возраста официально трудоустроены ${ }^{9}$ ), три четверти пожилых в России живут в семьях, а доля пенсионеров среди вкладчиков российских банков составляет около $60 \%{ }^{10}$. Уровень материальной обеспеченности пожилых людей

7 Федеральный закон от 24 ноября 1996 г. №132-Ф3 «Об основах туристской деятельности в Российской Федерации» (с изменениями и дополнениями).

8 Старшее поколение [Электронный ресурс] // Федеральная служба государственной статистики. URL: https://rosstat.gov.ru/folder/13877.

9 Пожилые люди России назвали свои главные проблемы [Электронный ресурс]// РБК. 6 октября 2017 г. URL: https://www.rbc.ru/society/06/10/2017/59d71ba29a794779b25168e2.

10 Вкладчик или домовладелец: кто безбедно живет на пенсии? [Электронный ресурс] // Banki.ru. URL: https://www.banki.ru/news/daytheme/?id=10891116. 
неоднороден по всей стране, что сказывается на уровне вовлеченности в туристские практики: «Доля путешествующих в Ростовской области не отличается от других регионов России. Более высокие показатели будут только в Москве и Санкт-Петербурге, там выме средний уровень жизни населения» (эксперт №3). Однако в целом туристские практики старшего поколения в России носят бюджетный характер: «Клише уже такое: в России турист 60+ — это бюджетный турист» (эксперт №5), и это отличает нашу страну от, например, Испании, где старшая возрастная группа обладает более высокой, чем у молодых, покупательской способностью [4].

Следующая группа факторов, влияющих на вовлеченность в туристские практики, связана с состоянием здоровья старшего поколения (физиологический фактор): «Если есть ограничения здоровья, какие-то хронические заболевания, то будет дискомфорт, если, например, путешествуешь в горной местности, где активно меняется давление даже в течение суток» (эксперт №2); «Ocновная проблема в таком возрасте - это здоровье» (эксперт №6). В России на 2021 г. насчитывается почти 7 млн. инвалидов в возрасте старше 60 лет, еще 1,7 млн. - в группе 51-60 лет ${ }^{11}$, а около 50\% россиян (всех во3растов) имеют хронические заболевания ${ }^{12}$. Вместе с тем туриндустрия сегодня движется по пути увеличения физической доступности объектов и предлагает продукты, направленные на оздоровление, санаторно-курортное лечение, туры для людей с различными ограничениями здоровья.

В качестве составляющей культурного капитала можно рассмотреть владение информационно-коммуникационными технологиями. Рынок туристических услуг прочно освоил интернет-пространство, и некоторые турфирмы отказываются от продаж туров в очном формате офиса: «В Москве многие отказались от офисов, перешли на онлайн. Они заведомо отказываются от определенной категории туристов, потому что именно 60+ в основном все еще приходят в офисы, платят наличнылми» (эксперт №5). Хотя доля пожилых людей, осваивающих компьютер, ежегодно возрастает, в возрастной когорте старше 65 лет доля пользователей интернета составляет всего около $6 \%{ }^{13}$. Эксперт №2 отмечает закономерность: «Те, кто используют интернет, активнее путешествуют, поскольку у них больше доступ к услугам, которые предоставляются». Цифровое неравенство становится причиной слабой доступности туризма для старшего поколения: «Повсеместная автоматизачия, информатизачия... Элементарно зарегистрироваться в аэропорту, если там применяются электронные системы регистрации, а не обычная стойка, может быть проблемой для старшего поколения» (эксперт №1).

Исследуя факторы внешней среды и их влияние на туризм старшего поколения, в современных условиях следует прежде всего упомянуть эпидемиологические факторы. Численность туристов значительно сократилась во всех возрастных группах, но эксперты Ростуризма прогнозируют восстановление внутреннего турпотока к концу 2021 г. $^{14}$. Однако в сегменте старшего поколения быстрое восстановление маловероятно: «Очень резко снизился проиент путешествуюших именно в этой группе. Я считаю, что лет 10 уйдет на возврат к нормальным показателям» (эксперт №2); «Сейчас я наблюдаю уменьшение количества пенсионеров, которые ездят. До пандемии было больше» (эксперт №6). В то же время оздоровительный туризм, в т.ч. санаторно-курортное лечение, может стать средством реабилитации после перенесенного заболевания коронавирусом.

Группой факторов, важной при выборе типа практики (международная/внутрироссийская) и конкретного направления путе-

11 Численность инвалидов по возрастным группам в разрезе субъектов РФ [Электронный ресурс] // Пенсионный Фонд РФ. URL: https://sfri.ru/analitika/chislennost/chislennost/chislennost-po-vozrastu?territory=undefined.

12 Около $50 \%$ прошедших диспансеризацию россиян имеют хронические заболевания [Электронный ресурс] // РИА Новости. 14 октября 2019 г. URL: https://ria.ru/20191014/1559748078.html.

13 Треть пожилых людей в России являются активными пользователями интернета [Электронный ресурс] // Федеральная служба государственной статистики. 1 октября 2019 г. URL: https://rosstat.gov.ru/folder/313/ document $/ 63640$.

14 Ростуризм: около 63 млн. человек путешествовали по России с января по июль [Электронный ресурс] // Интерфакс. 2 сентября 2021 г. URL: https://tourism.interfax.ru/ru/news/articles/81584/. 
шествия, выступают факторы политические. Эксперты подчеркивают, что для пожилых людей они более существенны, чем для других возрастных когорт: «Политическая ситуация очень сильно влияет на пожильх. На молодежь - нет, они не смотрят телевизор, не слушают это все. А пожилое население в ситуации с пандемией, с политической ситуаџией всегда задает вопросы» (эксперт №6). Эксперт №2 рассуждает о причинах важности политических факторов для пожилых, связанных с габитусом: «Может быть, это воспитание такое было заложено, такая идеологическая платформа у этих людей. Они очень подвержены политическим отночениям. Недоброжелательность руководства странь к россиянам влияет так, что они категорически в эту стану не поедут».

$\mathrm{C}$ политическими факторами тесно связано влияние средств массовой информации (информационные факторы). Основным источником информации для пожилых людей остается телевидение: в возрастной группе 60+ федеральные каналы «смотрят часто» $87 \%$ респондентов опроса ВЦИОМ 2017 г. $^{15}$ Было выявлено негативное влияние новостных телепередач на туризм старшего поколения: «Если говорить об информачионном поле всевозможных ток-шоу и новостей, то здесь обратный популяризации эффект: "Сидите дома, никуда не суйтесь”" (эксперт №1); «Мне кажется, они очень умело воздействуют на эту аудиторию, транслируют негатив, находят каких-то недовольных туристов в Туриии. И это все показывается по федеральнылм каналам» (эксперт №5). Представители старшего поколения не являются однородной группой в части доверия тем или иным СМИ, и степень воздействия на туристские практики зависит от психики конкретного человека: «Люди внушаемые поддаются пропаганде СМИ, а у некоторых она вызывает обратную реакиию. У всех все по-разному. Но, конечно, СМИ создают фон, установку, и однозначно, большая часть людей будет попадать под ту волну, которая создается СМИ. ... СМИ - это манипуляциия мнением, и в туризме это практикуется» (эксперт №1). Также необходимо понимать, что некоторые угрозы, освещаемые в новостных программах, являются объективными и могут представлять реальную опасность для туристов.

Познавательные телепередачи о путешествиях, тревел-шоу («Непутевые заметки», «Мир наизнанку», «Орел и решка», «Жизнь других» и т.д.) способствуют популяризации туризма: «Передачи, в которых уделяется внимание пожилым людям, та же “Жизнь других”, для некоторых пенсионеров могут быть стимулом для поездок, посмотреть, как живут их ровесники за рубежом» (эксперт №1). Однако эксперт №2 замечает, что такие программы не ориентированы на пожилых людей: «В основном мы что видим? Красивые ролики, где отображаются $u$ популяризируются молодые возрастные группь. А для пожилого населения мало чего предлагается в СМИ в плане поездок, где пожилое население будет чувствовать себя зашищенно». Эксперт №6 подтверждает необходимость учитывать особенности туристских потребностей пожилых людей при создании телепередач: “" “орел и решка” - это развлекательная программа, ведущие там c вылек прыгают. Пожильм интересно найти красоту, впечатления, они заботятся о здоровье. Просветительская работа какаято, может, и есть, но для пенсионеров нет». Таким образом, СМИ формируют социальное поле, среду, в которой осуществляются (или же не осуществляются) туристские практики.

Отношение социума к старшему поколению, старости и восприятие себя пожилым человеком в этом обществе также характеризует социальное поле туристских практик. По результатам упомянутого выше исследования ВЦИОМ 2020 г., среди проблем, с которыми сталкиваются пожилые люди, помимо бедности, низких пенсий и ухудшения здоровья, присутствуют и такие, как ощущение ненужности, невостребованности в обществе (19\%), одиночество (17\%), неуважение со стороны молодых (12\%), a также отсутствие активной деятельности (7\%), безразличие со стороны государства, государственных структур (5\%), отсутствие

15 ВЦИОМ: большинство россиян узнают новости по ТВ [Электронный ресурс] // ТАСС. 7 августа 2017 г. URL: https://tass.ru/obschestvo/4466784. 
интереса к жизни $(3 \%)^{16}$. Наличие этих проблем и их влияние на туризм пожилых людей подтверждают и эксперты: «Отсутствие социиальных механизмов психологической и моральной поддержки, отношение социума к пожильм как к “уже пожившим”, общая соичиальная индифферентность к пожильмм (эксперт №3); «Вот такую позищию у нас заняло государство: мол, вы вот на пенсию вылили, как рабочая сила нам не нужны, вот и доживайте, вы нам не интересныл. И это прослеживается абсолютно везде» (эксперт №5). В результате в российском обществе «активно путешествующий пенсионер, хорошо выглядящий, - это исключение, которое вызывает удивление. Негатива нет, но это не воспринимается как норма» (эксперт №1). «Туризм старшего поколения, - отмечает эксперт №4, - это такая сложная шттука для нашего менталитета, непривычная, мы в России только начинаем об этом думать». Проблема отношения к старости и пожилым людям в российском обществе, безусловно, гораздо обширнее сферы туризма и затрагивает и другие повседневные жизненные практики старшего поколения, влияя на восприятие пожилым человеком своего социального статуса.

К внешним факторам формирования туристских практик также относится уровень развития туриндустрии в стране, который включает в себя не только наличие необходимых объектов (средств размещения, транспортных средств, объектов общественного питания, наполнения программы тура и т.д.), но и их доступность для разных групп вне зависимости от особенностей здоровья, подготовку персонала для работы с пожилыми людьми, функционирование программ социального туризма и т.д. Оценивая туриндустрию России с точки зрения сформированности условий для развития туризма старшего поколения, эксперты отмечали несоответствие предложения материальным возможностям и потребностям пожилых людей [5]: «У нас очень мало санаториев, доступных мест отдыха для насе- ления пожилого, чтобы были предоставлены хорошие условия проживания» (эксперт №2); «Я ни разу не видела, по крайней мере, в предложениях по Северному Кавказу или еще где-то маршрутов для пожильх людей» (эксперт №4). Как отмечает эксперт №1, в России туриндустрия ориентирована на другие возрастные категории: «Объекты размещения ориентированы в большей степени на семейный отдых, отдых молодежи, и инфраструктура самих туристских иентров рассчитана на эту публику». Существуют сложности с доступностью транспортной инфраструктуры: «Рассмотрим, например, наши вокзаль, это тоже сложная история. Не в каждом автобусе откидываются спинки, высока амортизачия наших средств передвижения. Опять же лестницы, если тыл с чемоданом» (эксперт №3).

Учитывая сравнительно небольшой экономический капитал российских пенсионеров, можно сказать, что решение задачи вовлечения пожилого населения в туризм может осуществиться исключительно через поиск путей финансирования либо увеличения доступности туристских услуг для пожилого населения [6]. При анализе действующей в Ростовской области социальной программы санаторно-курортного лечения для льготных категорий (инвалиды, участники Великой Отечественной войны, лица, подвергшиеся воздействию радиации вследствие катастрофы на Чернобыльской АЭС и др.) было выявлено следующее несоответствие: норматив финансовых затрат в месяц на одного гражданина, получающего государственную социальную помощь по санаторно-курортному лечению, в 2021 г. составляет 144,37 руб. в месяц (1732,44 руб. в год), а стоимость одного дня пребывания в санаторно-курортных учреждениях в 2021 г. (по данным Фонда социального страхования) - 1348,10 руб. ${ }^{17}$. При этом минимальный срок пребывания в санаториях из перечня санаторно-курортных организаций, осуществляющих лечение граждан, имеющих право на получение набора социальных услуг, составляет 18 дней. Та-

16 Продолжительность жизни в России: желания и реальность [Электронный ресурс] // ВЦИОМ. 4 декабря 2020 г. URL: https://old.wciom.ru/index.php?id=236\&uid=10659.

17 Обеспечение граждан получателей социальных услуг путевками на санаторно-курортное лечение [Электронный ресурс] // Ростовское региональное отделение Фонда социального страхования РФ. URL: https://r61.fss. $\mathrm{ru} /$ directions/39311/index.shtml. 
ким образом, лишь некоторая доля пожилых людей имеет право на социальную поддержку в сфере туризма, и при этом выделяемая сумма не соответствует действующим предложениям санаториев. В то же время в некоторых регионах России перечень льготных категорий шире: например, в Москве и Московской области таким правом обладают ветераны труда.

На увеличение доступности туристских услуг направлена программа «Туристический кешбэк», предназначенная для стимулирования внутреннего туризма: при оплате поездки онлайн картой «Мир» $20 \%$ от стоимости тура по России можно вернуть. Эксперты оценивают данную программу неоднозначно: «Кешбэк очень хорошо простимулировал туризм. У меня достаточно много заявок было именно по кешбэку, может быть, в силу того, что не такие большие пенсии у нас в России» (эксперт №6). С другой стороны, отели, вошедшие в число партнеров программы, поднимали цены на свои услуги. Кроме того, реализация программы в онлайн-формате и при условии получения карты «Мир» сложна для пожилых людей, не обладающих достаточными техническими навыками.

Федеральный проект «Разработка и реализация программы системной поддержки и повышения качества жизни граждан старшего поколения» (2019-2024 гг.), реализуемый в рамках проекта «Демография», не включает в себя развитие туристской активности пожилого населения. Среди заложенных в проекте показателей - обеспечение системой долговременного ухода, доступности медицинской помощи, проведение диспансеризации, создание гериатрических центров и т.д. Законодательно транслируется медикалистский подход к старости, а поддержание социальной активности, укрепление социального здоровья остаются за кадром. Эксперты заявляют об отсутствии федеральных и региональных программ по поддержке туризма старшего поколения: «Их нет, только если частная история с грантами, даже если мы возьмем Стратегию развития туризма. Детский туризм у нас на флаг поднят, а вот о возрастном туризме для старшего поколения и полстрочки я не видела» (эксперт №4).
Заключение. Таким образом, низкая вовлеченность старшего поколения в России в туристские практики обуславливается комплексом факторов, которые не сводятся к очевидным экономическим (низкие пенсии) или эпидемиологическим. Барьерами выступают плохое состояние здоровья, недостаточное развитие информационно-коммуникационных навыков у значительной части пожилых людей, а также политические факторы и фокус СМИ на угрозах и опасностях, поджидающих туриста. Не способствуют повышению туристской активности старшего поколения отсутствие специализированных федеральных и региональных программ, несоответствие предлагаемых туристских услуг материальным и физиологическим возможностям и потребностям пожилых людей. Многофакторность и сложность данной проблемы взывают к необходимости глубокой социологической экспертизы, которая позволит своевременно выявлять потребности в туристских практиках этой возрастной группы, ее ожидания, планы, опасения и причины, препятствующие реализации туристских практик и в соответствии с ними выстраивать систему стратегий повышения туристской активности.

\section{Список источников}

1. Бурдье П. Практический смысл. СПб.: Алетейя, 2001. 562 с.

2. Giddens A. The constitution of society: Outline of the theory of structuration. Cambridge: Polity Press, 1984.

3. Bourdieu P. Structures, Habitus, Practices/ The Logic of Practice. Les Editions de Minuit, 1980.

4. Sanchez M.N.L., Gonzalez M.E.A., Vila T.D. Approximation to the senior tourist profile and behaviour // Revista Galega de Economia. 2014. vol. 23. №2. Pp. 69-90.

5. Максимова О.А., Малышева Е.В. Возрастная дифференциация удовлетворенности потребителей в сфере туризма // Вестник Нижегородского университета им. Н.И. Лобачевского. Серия: Социальные науки. 2015. №1 (37). C. 139-147.

6. Грошев И.В. Туризм для лиц пожилого возраста: монография / И.В. Грошев, Е.П. Корчагин. М.: ИНФРА-М, 2021. 303 с. 


\section{References}

1. Burd'e P. Prakticheskij smysl [Practical sense]. Saint Petersburg: Aletejja, 2001. 562 p. (In Russ.).

2. Giddens A. The constitution of society: Outline of the theory of structuration. Cambridge: Polity Press, 1984.

3. Bourdieu P. Structures, Habitus, Practices/ The Logic of Practice. Les Editions de Minuit, 1980.

4. Sanchez M.N.L., Gonzalez M.E.A., Vila T.D. Approximation to the senior tourist profile and behaviour // Revista Galega de Economia. 2014. vol. 23. №2. Pp. 69-90.
5. Maksimova O.A., Malysheva E.V. Vozrastnaja differenciacija udovletvorennosti potrebitelej $\mathrm{V}$ sfere turizma [Age differentiation of consumer satisfaction in tourism]. Vestnik Nizhegorodskogo universiteta im. N.I. Lobachevskogo. Serija: Social'nye nauki [Bulletin of the Nizhny Novgorod University named after N.I. Lobachevsky. Series: Social Sciences]. 2015; 1 (37): 139-147. (In Russ.).

6. Groshev I.V. Turizm dlya lic pozhilogo vozrasta: monografiya [Tourism for the elderly: monograph]/ I. V. Groshev, E.P. Korchagin. Moscow: INFRA-M, 2021; 303 p. (In Russ.).

Статья поступила в редакиию 06.09.2021; одобрена после рещензирования 21.09.2021; принята к публикации 27.09.2021.

The article was submitted on 06.09.2021; approved after reviewing on 21.09.2021; accepted for publication on 27.09.2021.

\section{ИНФОРМАЦИЯ ОБ АВТОРАХ}

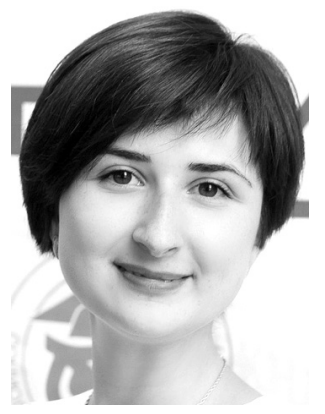

Черевкова Алена Игоревна - аспирант, специалист по учебно-методической работе, Институт социологии и регионоведения, Южный федеральный университет.

Россия, г. Ростов-на-Дону, ул. Пушкинская, 160

Alena I. Cherevkova - Postgraduate Student, Specialist in educational and methodical work, Institute of Sociology and Regional Studies, Southern Federal University.

160 Pushkinskaya st., Rostov-on-Don, Russia 